\title{
Difference in Tumor Area as a Predictor of a Pathological Complete Response for Patients With Locally Advanced Rectal Cancer
}

\author{
Ji Hyeong Song, Yo-Han Park, Sang Hyuk Seo, Anbok Lee, Kwang Hee Kim, Min Sung An, \\ Ki Beom Bae, Kwan Hee Hong, Jin Won Hwang ${ }^{1}$, Ji Hyun Kim ${ }^{1}$, Hyun Seok Jung ${ }^{2}$, Ki Jung Ahn ${ }^{3}$ \\ Departments of Surgery, ${ }^{1}$ Internal Medicine, ${ }^{2}$ Radiology, and ${ }^{3}$ Radiation Oncology, Inje University Busan Paik Hospital, Inje University \\ College of Medicine, Busan, Korea
}

Purpose: This study was conducted to discover the clinical factors that can predict pathologically complete remission (pCR) after neoadjuvant chemoradiotherapy (CRT), so that those factors may help in deciding on a treatment program for patients with locally advanced rectal cancer.

Methods: A total of 137 patients with locally advanced rectal cancer were retrospectively enrolled in this study, and data were collected retrospectively. The patients had undergone a total mesorectal excision after neoadjuvant CRT. Histologic response was categorized as pCR vs. non-pCR. The tumor area was defined as (tumor length) $\times$ (maximum tumor depth). The difference in tumor area was defined as pre-CRT tumor area - post-CRT tumor area. Univariate and multivariate logistic regression analyses were conducted to find the factors affecting pCR. A P-value $<0.05$ was considered significant. Results: Twenty-three patients (16.8\%) achieved pCR. On the univariate analysis, endoscopic tumor circumferential rate $<50 \%$, low pre-CRT T \& N stage, low post-CRT T \& N stage, small pretreatment tumor area, and large difference in tumor area before and after neoadjuvant CRT were predictive factors of $\mathrm{pCR}$. A multivariate analysis found that only the difference in tumor area before and after neoadjuvant CRT was an independent predictor of $\mathrm{pCR}(\mathrm{P}<0.001)$.

Conclusion: The difference in tumor area, as determined using radiologic tools, before and after neoadjuvant CRT may be important predictor of pCR. This clinical factor may help surgeons to determine which patients who received neoadjuvant CRT for locally advanced rectal cancer should undergo surgery.

\section{Keywords: Rectal neoplasms; Chemoradiotherapy}

\section{INTRODUCTION}

In patients with locally advanced rectal cancer, the standard treatment is a total mesorectal excision at $4-8$ weeks after neoadjuvant chemoradiotherapy (CRT). Compared with postoperative CRT,

Received: July 18,2017 - Accepted: October 2, 2017

Correspondence to: Ki Beom Bae, M.D.

Division of Colorectal Surgery, Department of Surgery, Inje University Busan Paik Hospital, Inje University College of Medicine, 75 Bokji-ro, Busanjin-gu, Busan 47392, Korea

Tel: +82-51-890-6352, Fax: +82-51-898-9427,E-mail: bkbsur@hanmail.net

(c) 2017 The Korean Society of Coloproctology

This is an open-access article distributed under the terms of the Creative Commons Attribution NonCommercial License (http://creativecommons.org/licenses/by-nc/4.0) which permits unrestricted noncommercial use, distribution, and reproduction in any medium, provided the original work is properly cited. preoperative CRT has a relatively low toxicity, reduces the local recurrence rate, and enhances the chance of preserving the anal sphincter; nevertheless, it has no effect on long-term survival [1, 2 ]. Of the patients who undergo neoadjuvant CRT, 10\%-30\% show a pathologically complete response (pCR) [3-7]. In these patients, the oncological outcome is better than it is in patients who do not achieve a pCR $[4,8-10]$.

In this regard, Habr-Gama et al. [11] suggested a "watch-andwait" strategy, in which patients who show a clinical complete response undergo close clinical and radiological follow-up rather than immediate surgery. Recent studies reported that the "watchand-wait" strategy resulted in prognoses similar to those achieved with neoadjuvant CRT and surgery [12-15]. If pCRs can be predicted preoperatively, then morbidities, such as postoperative complications, permanent stoma, sexual dysfunction, and urinary 
dysfunction, may be avoided. Unfortunately, no clinical data, including endoscopic and radiological studies, can accurately predict a pCR [16-19]. For these reasons, this study examined the clinical predictors of a pCR after neoadjuvant CRT to help determine a treatment program for the management of patients with locally advanced rectal cancer.

\section{METHODS}

This retrospective study enrolled 137 patients who had undergone a total mesorectal excision after neoadjuvant CRT at the Department of Surgery, Inje University Busan Paik Hospital, between March 2000 and December 2015. All patients had a pathologically confirmed adenocarcinoma based on pretreatment colonoscopy. The clinical stage was established using pelvis magnetic resonance imaging (MRI), but for those who had not undergone MRI, abdomen and pelvis computed tomography (APCT) was used to establish the clinical stage. The sensitivity and the specificity of pelvis MRI are well known to be better than those of APCT in $\mathrm{T} \& \mathrm{~N}$ staging of rectal cancer, but some patients refuse to undergo pelvis MRI because of their economic status. Therefore, every patient had undergone pre/post CRT APCT, but only about half had undergone MRI. This study included patients whose rectal cancers were located within $10 \mathrm{~cm}$ above the anal verge and were in stage $\mathrm{T} 3$ or $\mathrm{T} 4$ and/or who were lymph-node positive. Those with distant metastases or other pretreatment malignancies were excluded. The Institutional Review Board of Inje University Busan Paik Hospital approved this study (approval number: 160237). Formal consent of the patients is not required for this type of study.

External beam radiotherapy was performed with the patient in the prone position using a belly board. A 3-field technique and a 3-dimensional informal technique were used in all patients. The patients received a total dose of $50.4 \mathrm{~Gy}$, at a once-daily dose of 1.8 Gy. All patients were treated with $1.8-\mathrm{Gy}$ fractions. All patients were treated concurrently with either 2 cycles of bolus infusion 5 -fluoruracil (5-FU) at $425 \mathrm{mg} / \mathrm{m}^{2}$ per day, 5 times weekly, every 4 weeks or with capecitabine at $825 \mathrm{mg} / \mathrm{m}^{2}$ twice a day, 5 days per week for 6 weeks. Among the patients assigned to preoperative treatment, surgery was scheduled to take place 6 weeks after the completion of CRT. Four cycles of bolus infusion 5-FU at $425 \mathrm{mg} /$ $\mathrm{m}^{2}$ per day, 5 times weekly, every 4 weeks were started 4 weeks after surgery.

One colonoscopist and 1 radiologist retrospectively reviewed the colonoscopic findings and the results of the imaging studies (APCT \& MRI). This was done to minimize any possible bias because interpretation of the images can be subjective and may vary between doctors. The colonoscopist measured the endoscopic circumferential rate and classified the tumor's location and morphology, and the radiologist depicted the imaging studies (APCT \& MRI). He measured pre CRT T \& N stage, post CRT T \& N stage, the tumor's area (tumor length $\times$ maximum tumor depth), and the difference in tumor area. The tumor area was measured using MRI in the presence of pre/post CRT pelvis MRI and using APCT in the absence of pre/post CRT pelvis MRI. (The difference in tumor area $=$ pre CRT tumor area - post CRT tumor area).

All values are presented as means \pm standard deviations for continuous variables and as numbers and percentages for discrete variables. We performed the $t$-test or the Wilcoxon rank sum test and the chi-square test or Fisher exact test, as appropriate. A receiver operating characteristic curve analysis was used in order to identify the optimal cutoff value of the difference in tumor area that could predict a pCR. Univariate and multivariate logistic regression analyses were conducted to identify the factors predictive of a pCR. The variables with P-values $<0.05$ in the univariate analyses were used in the multivariate analyses. A P-value $<0.05$ was considered significant. SAS ver. 9.3 (SAS Institute Inc., Cary, NC, USA) was used for the statistical analysis.

\section{RESULTS}

Table 1 summarizes the patients' demographics and the tumors' characteristics. Of the 137 patients who received neoadjuvant CRT, 23 (16.8\%) achieved a pCR. The patients were divided into the pCR $(n=23)$ and the non-pCR $(n=114)$ groups for comparison. Patients with an endoscopic circumferential rate below 50\% had a significantly higher $\mathrm{pCR}$ rate than did those with a rate over $50 \%(\mathrm{P}<0.001)$. Moreover, the lower the pre-CRT T $(\mathrm{P}=0.001)$ and $\mathrm{N}(\mathrm{P}=0.001)$ stages and the post-CRT T $(\mathrm{P}<0.001)$ and $\mathrm{N}(\mathrm{P}$ $=0.004)$ stages were, the higher the $\mathrm{pCR}$ rate was. In addition, the smaller the tumor area (tumor length $\times$ maximum tumor depth) measured pre-CRT using CT or MRI was, the higher the $\mathrm{pCR}$ rate $(\mathrm{P}<0.001)$ was (Table 1$)$. No other significant differences between the 2 groups were noted.

The optimal cutoff value of the difference in tumor area was 574 . The sensitivity and the specificity were $13 \%$ and $64 \%$ (odds ratio [OR], 3.774; 95\% confidence interval [CI], 1.049-13.364; P $=0.042)$. Fig. 1 shows the receiver operating characteristic $(\mathrm{ROC})$ curves of the difference in tumor area to predict pathologically complete response. Table 2 summarizes the results of the univariate and the multivariate analyses. On the univariate analyses, an endoscopic tumor circumferential rate $<50 \%(\mathrm{P}=0.004)$, low preCRT T $(\mathrm{P}=0.003)$ and $\mathrm{N}(\mathrm{P}=0.011)$ stage, a low post-CRT T $(\mathrm{P}$ $<0.001)$ and $\mathrm{N}(\mathrm{P}=0.013)$ stage, a small pretreatment tumor area, and a large difference in tumor area before and after neoadjuvant CRT $(\mathrm{P}<0.001)$ were predictors of a PCR. Multivariate analyses revealed that the difference in tumor area before and after neoadjuvant CRT was the only independent predictor of a pCR (OR, 0.996; 95\% CI, 0.993-0.998; P < 0.001).

\section{DISCUSSION}

This study investigated predictors of a pCR by investigating the patients' characteristics, pre-CRT colonoscopic findings, pre- and 
Table 1. Patient demographics and tumor characteristics

\begin{tabular}{|c|c|c|c|c|}
\hline Variable & Total $(n=137)$ & $\mathrm{pCR}(\mathrm{n}=23)$ & Non-pCR $(n=114)$ & P-value \\
\hline \multicolumn{5}{|l|}{ Sex } \\
\hline Female & $48(35.0)$ & $6(26.1)$ & $42(36.8)$ & 0.324 \\
\hline Male & $89(65.0)$ & $17(73.9)$ & $72(63.2)$ & \\
\hline Age (yr) & $64.49 \pm 10.77$ & $64.57 \pm 11.57$ & $64.47 \pm 10.65$ & 0.971 \\
\hline$<65$ & $72(52.6)$ & $13(56.5)$ & $59(51.8)$ & 0.676 \\
\hline$\geq 65$ & $65(47.4)$ & $10(43.5)$ & 55 (48.2) & \\
\hline \multicolumn{5}{|l|}{ Smoker } \\
\hline No & 109 (79.6) & $16(69.6)$ & 93 (81.6) & 0.193 \\
\hline Yes & $28(20.4)$ & $7(30.4)$ & $21(18.4)$ & \\
\hline \multicolumn{5}{|l|}{ Diabetes mellitus } \\
\hline No & $114(83.2)$ & 19 (82.6) & 95 (83.3) & 0.932 \\
\hline Yes & $23(16.8)$ & $4(17.4)$ & $19(16.7)$ & \\
\hline \multicolumn{5}{|l|}{ Hypertension } \\
\hline No & $100(73.0)$ & 18 (78.3) & $82(71.9)$ & 0.533 \\
\hline Yes & $37(27.0)$ & $5(21.7)$ & $32(28.1)$ & \\
\hline ASA PS classification grade & & & & 0.956 \\
\hline I & $33(24.1)$ & $5(21.7)$ & $28(24.6)$ & \\
\hline$\|$ & $93(67.9)$ & $16(69.6)$ & 77 (67.5) & \\
\hline III & $11(8.0)$ & $2(8.7)$ & $9(7.9)$ & \\
\hline \multicolumn{5}{|l|}{ Differentiation } \\
\hline Moderate & $82(59.9)$ & $13(56.5)$ & $69(60.5)$ & 0.614 \\
\hline Poor & $5(3.6)$ & $1(4.3)$ & $4(3.5)$ & \\
\hline Well & $36(26.3)$ & $8(34.8)$ & $28(24.6)$ & \\
\hline Mucinous & $14(10.2)$ & $1(4.3)$ & $13(11.4)$ & \\
\hline \multicolumn{5}{|l|}{ Pre-CRT CEA } \\
\hline$\leq 5$ & $66(48.2)$ & $9(39.1)$ & $57(50.0)$ & 0.341 \\
\hline$>5$ & $71(51.8)$ & $14(60.9)$ & $57(50.0)$ & \\
\hline \multicolumn{5}{|l|}{ Post-CRT CEA } \\
\hline$\leq 5$ & $102(74.5)$ & $16(69.6)$ & $86(75.4)$ & 0.556 \\
\hline$>5$ & 35 (25.5) & $7(30.4)$ & $28(24.6)$ & \\
\hline \multicolumn{5}{|l|}{ Interval time CTx } \\
\hline $\mathrm{FL}$ & $58(42.3)$ & $13(56.5)$ & 45 (39.5) & 0.367 \\
\hline Capecitabine & $79(57.7)$ & $10(43.5)$ & $69(60.5)$ & \\
\hline \multicolumn{5}{|c|}{ Endoscopic circumferential rate } \\
\hline$<50 \%$ & $32(23.4)$ & $11(47.8)$ & $21(18.4)$ & 0.002 \\
\hline$\geq 50 \%$ & $105(76.6)$ & $12(52.2)$ & $93(81.6)$ & \\
\hline \multicolumn{5}{|l|}{ Location } \\
\hline Mid rectum & $54(39.4)$ & $7(30.4)$ & $47(41.2)$ & 0.334 \\
\hline Low rectum & $83(60.6)$ & $16(69.6)$ & $67(58.8)$ & \\
\hline Morphology & & & & 0.074 \\
\hline Protruding & 77 (56.2) & $8(34.8)$ & $69(60.5)$ & \\
\hline Flat/lst & $51(37.2)$ & $13(56.5)$ & 38 (33.3) & \\
\hline Depressed & $9(6.6)$ & $2(8.7)$ & $7(6.1)$ & \\
\hline
\end{tabular}


Table 1. Continued

\begin{tabular}{|c|c|c|c|c|}
\hline Variable & Total $(n=137)$ & $\mathrm{pCR}(\mathrm{n}=23)$ & Non-pCR $(n=114)$ & P-value \\
\hline \multicolumn{5}{|l|}{ Melanosis coli } \\
\hline No & $128(93.4)$ & 21 (91.3) & 107 (93.9) & 0.647 \\
\hline Yes & $9(6.6)$ & $2(8.7)$ & $7(6.1)$ & \\
\hline Pre-CRT T & & & & 0.001 \\
\hline $\mathrm{T} 2$ & $30(21.9)$ & 12 (52.2) & $18(15.8)$ & \\
\hline T3 & $101(73.7)$ & $11(47.8)$ & $90(78.9)$ & \\
\hline $\mathrm{T} 4$ & $6(4.4)$ & $0(0.0)$ & $6(5.3)$ & \\
\hline Pre-CRT N & & & & 0.006 \\
\hline NO & 27 (19.7) & $10(43.5)$ & $17(14.9)$ & \\
\hline N1 & $51(37.2)$ & $7(30.4)$ & $44(38.6)$ & \\
\hline N2 & $59(43.1)$ & $6(26.1)$ & $53(46.5)$ & \\
\hline Post-CRT T & & & & $<0.001$ \\
\hline TO & $18(13.1)$ & $12(52.2)$ & $6(5.3)$ & \\
\hline $\mathrm{T} 1$ & $13(9.5)$ & $6(26.1)$ & $7(6.1)$ & \\
\hline $\mathrm{T} 2$ & $42(30.7)$ & $3(13.0)$ & 39 (34.2) & \\
\hline T3 & $62(45.3)$ & $2(8.7)$ & $60(52.6)$ & \\
\hline $\mathrm{T} 4$ & $2(1.5)$ & $0(0.0)$ & $2(1.8)$ & \\
\hline Post-CRT N & & & & 0.004 \\
\hline NO & 71 (51.8) & 19 (82.6) & $52(45.6)$ & \\
\hline N1 & $44(32.1)$ & $2(8.7)$ & $42(36.8)$ & \\
\hline N2 & $22(16.1)$ & $2(8.7)$ & $20(17.5)$ & \\
\hline Difference in tumor area & $547.64 \pm 581.23$ & $182.87 \pm 382.39$ & $621.24 \pm 587.85$ & 0.001 \\
\hline
\end{tabular}

Values are presented as number (\%) or mean \pm standard deviation.

pCR, pathologically complete response; ASA PS, American Society of Anesthesiologists physical status; CRT, chemoradiotherapy; CEA, carcinoembryonic antigen; CTx, chemotherapy; FL, fluorouracil (5-FU), leucovorin (folic acid).

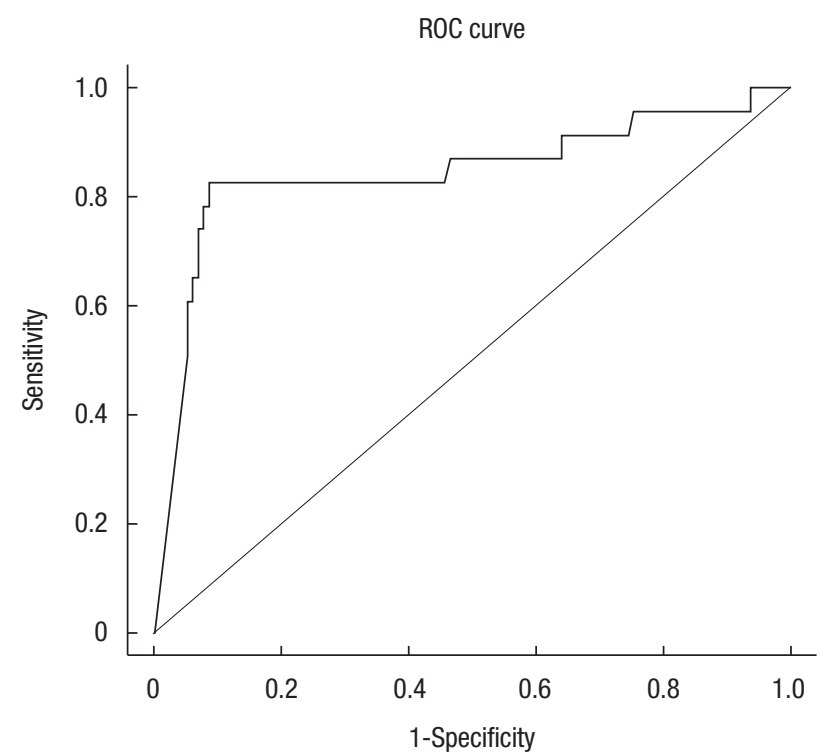

Fig. 1. Receiver operating characteristic (ROC) curves of the difference in tumor area to predict pathologically complete response.
post-CRT radiological findings and carcinoembryonic antigen levels, and tumor differentiation in locally advanced rectal cancer. The pCR rate in this study was $16.8 \%$, which is similar to the rates found in other randomized phase III trials [20-22].

Park et al. [23] investigated the predictors of a pCR in 249 patients with rectal cancer by using a digital rectal exam and colonoscopic findings and found a pCR rate of $12.9 \%$. Multivariate analyses showed that the pre-CRT movability $(\mathrm{P}=0.024)$, postCRT size $(\mathrm{P}=0.018)$, post-CRT morphology $(\mathrm{P}=0.023)$, and gross changes $(\mathrm{P}=0.009)$ were independent predictors of a pCR. They used colonoscopy to evaluate the pre-CRT circumferential rate, tumor morphology (protruding, flat, or depressed), and the presence of melanosis coli, and only the size-related circumferential rate had a significant relationship with $\mathrm{pCR}$ in the univariate analyses.

In a study of 297 rectal cancer patients, Garland et al. [24] reported that a decreased tumor size $(\mathrm{P}=0.036)$ and pretreatment clinical $\mathrm{N}$ stage $(\mathrm{P}=0.048)$ were predictors of a pCR. De Felice et al. [25] showed that a pretreatment tumor dimension less than 5 $\mathrm{cm}$ was predictive of a pCR; they estimated tumor size by using 
Table 2. Univariate and multivariate analyses with pCR

\begin{tabular}{|c|c|c|c|c|c|c|}
\hline \multirow{2}{*}{ Variable } & \multicolumn{3}{|c|}{ Univariate } & \multicolumn{3}{|c|}{ Multivariate } \\
\hline & $\mathrm{OR}$ & $95 \% \mathrm{Cl}$ & P-value & $\mathrm{OR}$ & $95 \% \mathrm{Cl}$ & P-value \\
\hline \multicolumn{7}{|l|}{ Sex } \\
\hline Female & Reference & & & & & \\
\hline Age (yr) & 1.001 & $0.960-1.044$ & 0.970 & & & \\
\hline$\geq 65$ & Reference & & & & & \\
\hline \multicolumn{7}{|l|}{ Smoker } \\
\hline Yes & 1.937 & $0.708-5.301$ & 0.198 & & & \\
\hline No & Reference & & & & & \\
\hline \multicolumn{7}{|l|}{ Diabetes mellitus } \\
\hline \multicolumn{7}{|l|}{ Hypertension } \\
\hline No & 1.405 & $0.481-4.102$ & 0.534 & & & \\
\hline Yes & Reference & & & & & \\
\hline ASA PS classification grade & & & 0.956 & & & \\
\hline I & Reference & $0.390-3.473$ & 0.786 & & & \\
\hline$\|$ & 1.164 & $0.205-7.556$ & 0.812 & & & \\
\hline III & 1.244 & & & & & \\
\hline Differentiation & & & 0.642 & & & \\
\hline Moderate & Reference & & & & & \\
\hline \multicolumn{7}{|l|}{ Post-CRT CEA } \\
\hline$>5$ & 1.344 & $0.502-3.599$ & 0.557 & & & \\
\hline$\leq 5$ & Reference & & & & & \\
\hline \multicolumn{7}{|l|}{ Interval time CTx } \\
\hline $\mathrm{FL}$ & 2.022 & $0.228-17.966$ & 0.528 & & & \\
\hline Capecitabine & Reference & & & & & \\
\hline \multicolumn{7}{|c|}{ Endoscopic circumferential rate } \\
\hline$<50 \%$ & 4.060 & $1.577-10.448$ & 0.004 & & & \\
\hline$\geq 50 \%$ & Reference & & & & & \\
\hline \multicolumn{7}{|l|}{ Location } \\
\hline Mid rectum & & & 0.337 & & & \\
\hline Low rectum & 1.603 & $0.612-4.201$ & & & & \\
\hline
\end{tabular}




\section{Coloproctology $\begin{array}{r}\text { Annals of } \\ \text { Ji Hyeong Song, et al. }\end{array}$}

Table 2. Continued

\begin{tabular}{|c|c|c|c|c|c|c|}
\hline \multirow{2}{*}{ Variable } & \multicolumn{3}{|c|}{ Univariate } & \multicolumn{3}{|c|}{ Multivariate } \\
\hline & $\mathrm{OR}$ & $95 \% \mathrm{Cl}$ & P-value & $\mathrm{OR}$ & $95 \% \mathrm{Cl}$ & P-value \\
\hline Morphology & & & 0.085 & & & \\
\hline Protruding & 0.406 & $0.072-2.297$ & 0.082 & & & \\
\hline Flat/lst & 1.197 & $0.220-6.508$ & 0.248 & & & \\
\hline Depressed & Reference & & & & & \\
\hline \multicolumn{7}{|l|}{ Melanosis coli } \\
\hline Yes & 1.456 & $0.283-7.502$ & 0.653 & & & \\
\hline No & Reference & & & & & \\
\hline Pre-CRT T & & & 0.003 & & & \\
\hline T2 & 8.784 & $0.133-49.816$ & 0.972 & & & \\
\hline T3 & 1.652 & $0.066-23.552$ & 0.981 & & & \\
\hline T4 & Reference & & & & & \\
\hline Pre-CRT N & & & 0.011 & & & \\
\hline NO & 5.196 & $1.645-16.413$ & 0.003 & & & \\
\hline N1 & 1.405 & $0.440-4.489$ & 0.335 & & & \\
\hline N2 & Reference & & & & & \\
\hline Post-CRT T & & & $<0.001$ & & & \\
\hline TO & 9.615 & $0.111-64.320$ & 0.975 & & & \\
\hline $\mathrm{T} 1$ & 4.333 & $0.076-46.983$ & 0.980 & & & \\
\hline T2 & 0.443 & $0.028-17.701$ & 0.993 & & & \\
\hline T3 & 0.207 & $0.019-13.525$ & 0.998 & & & \\
\hline T4 & Reference & & & & & \\
\hline Post-CRT N & & & 0.013 & & & \\
\hline NO & 3.654 & 0.779-17.139 & 0.004 & & & \\
\hline N1 & 0.476 & $0.062-3.629$ & 0.092 & & & \\
\hline N2 & Reference & & & & & \\
\hline Difference in tumor area & 0.996 & $0.993-0.998$ & $<0.001$ & 0.996 & 0.993-0.998 & $<0.001$ \\
\hline
\end{tabular}

pCR, pathologically complete response; OR, odds ratio; Cl, confidence interval; ASA PS, American Society of Anesthesiologists physical status; CRT, chemoradiotherapy; $\mathrm{CEA}$, carcinoembryonic antigen; CTx, chemotherapy; FL, fluorouracil (5-FU), leucovorin (folic acid).

$\mathrm{CT}$ and MRI and determined the tumor area (tumor length $x$ maximum tumor depth). We also showed that the pretreatment tumor area, pre- and post-CRT T and $\mathrm{N}$ stages, and difference in tumor area before and after neoadjuvant CRT had significant relationships with pCR in the univariate analyses. In the multivariate analyses, however, the difference in tumor area before and after neoadjuvant CRT was the only predictor of a $\mathrm{pCR}$.

Studies have reported differences in the role of the clinical N stage as a predictor of pCR. As mentioned above, Garland et al. [24] found that the pretreatment clinical $\mathrm{N}$ stage was predictive of a pCR while other studies found that it was not [23, 25-27]. This may be because, despite the improvement in imaging modalities, the accuracy of lymph-node assessment is still poor. In a systemic review and meta-analysis of 21 studies, Al-Sukhni et al. [28] sug- gested that MRI had poor accuracy in lymph-node assessment and reported a $77 \%$ sensitivity and a $71 \%$ specificity in terms of lymph-node positivity.

Some recent studies have reported a relationship between k-ras mutation and the response to neoadjuvant CRT. Chow et al. [29] showed that k-ras mutation was related to a low $\mathrm{pCR}$ rate in patients with locally advanced rectal cancer. Conversely, in a systemic review and meta-analysis, Clancy et al. [30] reported that kras mutation did not affect tumor down-staging or cancer-specific survival.

Our study was limited in that it was both a single-center study with a small sample size and a retrospective study based on a chart review. More patients received neoadjuvant CRT for rectal cancer in our center during the study period, but we excluded 
those who had not undergone post-CRT imaging studies or had refused surgery, thereby leaving 137 patients eligible for this study. A few studies have reported that the longer the interval between preoperative CRT and surgery is, the higher the rate of $\mathrm{pCR}$ is [ 31 , 32]. However, in our center, surgery is routinely preformed 6 weeks after preoperative CRT; therefore, we could not include the time interval as a variable. Moreover, because some patients refused posttreatment colonoscopy, we could not investigate the colonoscopic findings post-CRT.

In conclusion, we found that the difference in tumor area before and after neoadjuvant CRT, as determined radiologically, may be an important predictor of a pCR. Future studies of molecular markers and this clinical measurement may help surgeons select for surgery patients who have received neoadjuvant CRT for the treatment of locally advanced rectal cancer.

\section{CONFLICT OF INTEREST}

No potential conflict of interest relevant to this article was reported.

\section{ACKNOWLEDGMENTS}

This work was supported by a National Research Foundation of Korea (NRF) grant funded by the Korea government's Ministry of Science, ICT and Future Planning (MSIP) (No. 2017R1A2B4007725).

\section{REFERENCES}

1. Sauer R, Liersch T, Merkel S, Fietkau R, Hohenberger W, Hess C, et al. Preoperative versus postoperative chemoradiotherapy for locally advanced rectal cancer: results of the German CAO/ARO/ AIO-94 randomized phase III trial after a median follow-up of 11 years. J Clin Oncol 2012;30:1926-33.

2. Sauer R, Becker H, Hohenberger W, Rödel C, Wittekind C, Fietkau R, et al. Preoperative versus postoperative chemoradiotherapy for rectal cancer. N Engl J Med 2004;351:1731-40.

3. Roh MS, Colangelo LH, O'Connell MJ, Yothers G, Deutsch M, Allegra CJ, et al. Preoperative multimodality therapy improves disease-free survival in patients with carcinoma of the rectum: NSABP R-03. J Clin Oncol 2009;27:5124-30.

4. Maas M, Nelemans PJ, Valentini V, Das P, Rödel C, Kuo LJ, et al. Long-term outcome in patients with a pathological complete response after chemoradiation for rectal cancer: a pooled analysis of individual patient data. Lancet Oncol 2010;11:835-44.

5. Das P, Minsky BD. A watch-and-wait approach to the management of rectal cancer. Oncology (Williston Park) 2013;27:962-8.

6. Chawla S, Katz AW, Rauh SM, Monson JR. Can surgery be avoided after preoperative chemoradiation for rectal cancer in the era of organ preservation? Current review of literature. Am J Clin Oncol 2015;38:534-40.

7. Garcia-Aguilar J, Shi Q, Thomas CR Jr, Chan E, Cataldo P, Marcet J, et al. A phase II trial of neoadjuvant chemoradiation and local excision for T2N0 rectal cancer: preliminary results of the ACOSOG Z6041 trial. Ann Surg Oncol 2012;19:384-91.

8. Habr-Gama A, Perez RO, Nadalin W, Nahas SC, Ribeiro U Jr, Sil va E Sousa AH Jr, et al. Long-term results of preoperative chemoradiation for distal rectal cancer correlation between final stage and survival. J Gastrointest Surg 2005;9:90-9.

9. Rödel C, Martus P, Papadoupolos T, Füzesi L, Klimpfinger M, Fietkau R, et al. Prognostic significance of tumor regression after preoperative chemoradiotherapy for rectal cancer. J Clin Oncol 2005; 23:8688-96.

10. Yeo SG, Kim DY, Kim TH, Chang HJ, Oh JH, Park W, et al. Pathologic complete response of primary tumor following preoperative chemoradiotherapy for locally advanced rectal cancer: long-term outcomes and prognostic significance of pathologic nodal status (KROG 09-01). Ann Surg 2010;252:998-1004.

11. Habr-Gama A, Perez RO, Wynn G, Marks J, Kessler H, GamaRodrigues J. Complete clinical response after neoadjuvant chemoradiation therapy for distal rectal cancer: characterization of clinical and endoscopic findings for standardization. Dis Colon Rectum 2010;53:1692-8.

12. Maas M, Beets-Tan RG, Lambregts DM, Lammering G, Nelemans PJ, Engelen SM, et al. Wait-and-see policy for clinical complete responders after chemoradiation for rectal cancer. J Clin Oncol 2011;29:4633-40.

13. Habr-Gama A, Gama-Rodrigues J, São Julião GP, Proscurshim I, Sabbagh C, Lynn PB, et al. Local recurrence after complete clinical response and watch and wait in rectal cancer after neoadjuvant chemoradiation: impact of salvage therapy on local disease control. Int J Radiat Oncol Biol Phys 2014;88:822-8.

14. Smith JJ, Chow OS, Eaton A, Widmar M, Nash GM, Temple LK, et al. Organ preservation in patients with rectal cancer with clinical complete response after neoadjuvant therapy. J Clin Oncol 2015;33(3 Suppl):509.

15. Appelt AL, Pløen J, Harling H, Jensen FS, Jensen LH, Jørgensen JC, et al. High-dose chemoradiotherapy and watchful waiting for distal rectal cancer: a prospective observational study. Lancet Oncol 2015;16:919-27.

16. Kuo LJ, Chiou JF, Tai CJ, Chang CC, Kung CH, Lin SE, et al. Can we predict pathologic complete response before surgery for locally advanced rectal cancer treated with preoperative chemoradiation therapy? Int J Colorectal Dis 2012;27:613-21.

17. Perez RO, Habr-Gama A, Gama-Rodrigues J, Proscurshim I, Julião GP, Lynn P, et al. Accuracy of positron emission tomography/ computed tomography and clinical assessment in the detection of complete rectal tumor regression after neoadjuvant chemoradiation: long-term results of a prospective trial (National Clinical Trial 00254683). Cancer 2012;118:3501-11.

18. Guillem JG, Ruby JA, Leibold T, Akhurst TJ, Yeung HW, Gollub MJ, et al. Neither FDG-PET nor CT can distinguish between a pathological complete response and an incomplete response after neoadjuvant chemoradiation in locally advanced rectal cancer: a 
prospective study. Ann Surg 2013;258:289-95.

19. van der Paardt MP, Zagers MB, Beets-Tan RG, Stoker J, Bipat S. Patients who undergo preoperative chemoradiotherapy for locally advanced rectal cancer restaged by using diagnostic MR imaging: a systematic review and meta-analysis. Radiology 2013;269:10112.

20. Rödel C, Liersch T, Becker H, Fietkau R, Hohenberger W, Hothorn T, et al. Preoperative chemoradiotherapy and postoperative chemotherapy with fluorouracil and oxaliplatin versus fluorouracil alone in locally advanced rectal cancer: initial results of the German CAO/ARO/AIO-04 randomised phase 3 trial. Lancet Oncol 2012;13:679-87.

21. Aschele C, Cionini L, Lonardi S, Pinto C, Cordio S, Rosati G, et al. Primary tumor response to preoperative chemoradiation with or without oxaliplatin in locally advanced rectal cancer: pathologic results of the STAR-01 randomized phase III trial. J Clin Oncol 2011;29:2773-80.

22. Gérard JP, Azria D, Gourgou-Bourgade S, Martel-Laffay I, Hennequin $\mathrm{C}$, Etienne PL, et al. Comparison of two neoadjuvant chemoradiotherapy regimens for locally advanced rectal cancer: results of the phase III trial ACCORD 12/0405-Prodige 2. J Clin Oncol 2010;28:1638-44.

23. Park CH, Kim HC, Cho YB, Yun SH, Lee WY, Park YS, et al. Predicting tumor response after preoperative chemoradiation using clinical parameters in rectal cancer. World J Gastroenterol 2011; 17:5310-6.

24. Garland ML, Vather R, Bunkley N, Pearse M, Bissett IP. Clinical tumour size and nodal status predict pathologic complete response following neoadjuvant chemoradiotherapy for rectal cancer. Int J Colorectal Dis 2014;29:301-7.

25. De Felice F, Izzo L, Musio D, Magnante AL, Bulzonetti N, Pugliese F, et al. Clinical predictive factors of pathologic complete re- sponse in locally advanced rectal cancer. Oncotarget 2016;7: 33374-80.

26. Wallin U, Rothenberger D, Lowry A, Luepker R, Mellgren A. CEA - a predictor for pathologic complete response after neoadjuvant therapy for rectal cancer. Dis Colon Rectum 2013;56:859-68.

27. Kalady MF, de Campos-Lobato LF, Stocchi L, Geisler DP, Dietz D, Lavery IC, et al. Predictive factors of pathologic complete response after neoadjuvant chemoradiation for rectal cancer. Ann Surg 2009;250:582-9.

28. Al-Sukhni E, Milot L, Fruitman M, Beyene J, Victor JC, Schmocker S, et al. Diagnostic accuracy of MRI for assessment of T category, lymph node metastases, and circumferential resection margin involvement in patients with rectal cancer: a systematic review and meta-analysis. Ann Surg Oncol 2012;19:2212-23.

29. Chow OS, Kuk D, Keskin M, Smith JJ, Camacho N, Pelossof R, et al. KRAS and combined KRAS/TP53 mutations in locally advanced rectal cancer are independently associated with decreased response to neoadjuvant therapy. Ann Surg Oncol 2016;23:254855.

30. Clancy C, Burke JP, Coffey JC. KRAS mutation does not predict the efficacy of neo-adjuvant chemoradiotherapy in rectal cancer: a systematic review and meta-analysis. Surg Oncol 2013;22:10511.

31. Zeng WG, Liang JW, Wang Z, Zhang XM, Hu JJ, Hou HR, et al. Clinical parameters predicting pathologic complete response following neoadjuvant chemoradiotherapy for rectal cancer. Chin J Cancer 2015;34:468-74.

32. Choi E, Kim JH, Kim OB, Kim MY, Oh YK, Baek SG. Predictors of pathologic complete response after preoperative concurrent chemoradiotherapy of rectal cancer: a single center experience. Radiat Oncol J 2016;34:106-12. 